\title{
miR-335 Targets SIAH2 and Confers Sensitivity to Anti-Cancer Drugs by Increasing the Expression of HDAC3
}

\author{
Youngmi Kim ${ }^{1,2}$, Hyuna Kim ${ }^{1,2}$, Deokbum Park', and Dooil Jeoung ${ }^{1, *}$
}

\begin{abstract}
We previously reported the role of histone deacetylase 3 (HDAC3) in response to anti-cancer drugs. The decreased expression of HDAC3 in anti-cancer drug-resistant cancer cell line is responsible for the resistance to anti-cancer drugs. In this study, we investigated molecular mechanisms associated with regulation of HDAC3 expression. MG132, an inhibitor of proteasomal degradation, induced the expression of HDAC3 in various anti-cancer drugresistant cancer cell lines. Ubiquitination of HDAC3 was observed in various anti-cancer drug-resistant cancer cell lines. HDAC3 showed an interaction with SIAH2, an ubiquitin E3 ligase, that has increased expression in various anticancer drug-resistant cancer cell lines. miRNA array analysis showed the decreased expression of miR-335 in these cells. Targetscan analysis predicted the binding of miR-335 to the 3'-UTR of SIAH2. miR-335-mediated increased sensitivity to anti-cancer drugs was associated with its effect on HDAC3 and SIAH2 expression. miR-335 exerted apoptotic effects and inhibited ubiquitination of HDAC3 in anticancer drug-resistant cancer cell lines. miR-335 negatively regulated the invasion, migration, and growth rate of cancer cells. The mouse xenograft model showed that miR335 negatively regulated the tumorigenic potential of cancer cells. The down-regulation of SIAH2 conferred sensitivity to anti-cancer drugs. The results of the study indicated that the miR-335/SIAH2/HDAC3 axis regulates the response to anti-cancer drugs.
\end{abstract}

\section{INTRODUCTION}

Among the numerous HDACs, histone deacetylase-3 (HDAC3) is ubiquitously expressed and conserved in a wide range of species (Mahlknecht et al., 1999). HDAC3 forms large corepressor complexes containing N-CoR/SMRT and additional

\footnotetext{
${ }^{1}$ Department of Biochemistry, College of Natural Sciences, Kangwon National University, Chunchon 200-701, Korea, ${ }^{2}$ These authors contributed equally to this work.

${ }^{*}$ Correspondence: jeoungd@ @angwon.ac.kr
}

Received 23 February, 2015; revised 23 March, 2015; accepted 25 March, 2015; published online 22 May, 2015

Keywords: anti-cancer drug-resistance, miR-335, SIAH2, ubiquitination proteins ( $\mathrm{Li}$ et al., 2000). HDAC3 regulates the JNK pathway (Zhang et al., 2002), NF-kB activity (Chen et al., 2001), MAPK activation (Mahlknecht et al., 2004) and apoptosis (Bardai and D'Mello, 2011; Uo et al., 2009). It represses CREB3-mediate transcription and migration of metastatic breast cancer cells (Kim et al., 2010) and acts as a negative regulator of angiogenesis (Park et al., 2014a). HDAC3 confers sensitivity to anticancer drugs (Kim et al., 2014). HDAC3 expression is lower in various anti-cancer drug-resistant vs. anti-cancer drug-sensitive cancer cell lines (Kim et al., 2014). The molecular mechanism of anti-cancer drug sensitivity conferred by HDAC3 remains unknown.

The loss of Siah2 increases chemo-sensitivity (Wong et al., 2012). The E3 ubiqutin ligase activity of Siah2 is necessary for resistance to death receptor-mediated apoptosis (Christian et al., 2011). The Inhibition of Siah2 ubiquitin ligase blocks melanoma tumorigenesis (Shah et al., 2009). SIAH2 expression is upregulated in basal-like breast cancers via copy number changes and/or transcriptional activation by p53 (Chan et al., 2011). The inhibition of Siah2 activity reduces metastasis through HIF-1alpha (Qi et al., 2008). Siah2 regulates HIF1 alpha expression and response to hypoxia (Nakayama et al, 2004). SIAH2 diminishes p53 acetylation and transcriptional activity (Grishina et al., 2012). Loss of SIAH2 suppresses tumorigenesis in a LATS2-dependent manner in a xenograft mouse model (Ma et al., 2015). Knockdown of SIAH2 causes growth suppression and apoptosis induction in a p53independent mechanism (Hsieh et al., 2013). Blood vessel normalization in Siah2 (-/-) tumors resulted in an increased response to chemotherapy and prolonged survival (Wong et al., 2012). These reports collectively suggest the role of SIAH2 in tumorigenesis and the response to anti-cancer drugs. However, the molecular mechanisms associated with the effect of SIAH2 on the response to anti-cancer drugs remains largely unknown. MicroRNAs (miRNAs) are non-coding RNA molecules that mediate posttranscriptional gene regulation (Calin and Croce, 2006). miRNAs play important roles in tumor development by regulating the expression of various oncogenes and tumor suppressor genes (Calin and Croce, 2006; Xu et al., 2013). For example, miR-199a suppresses tumorigenicity and multidrug resistance of ovarian cancer-initiating cells (Cheng et al., 2012). miR-27a reverses the multidrug resistance phenotype by regulating the expression of MDR1and $\beta$-catenin (Chen et al., 2013). miR-146b-5p suppresses translation of EGFR, binds to the EGFR 3'-UTR, and inhibits migration of gliomas (Katakowski et

elSSN: 0219-1032

(c) The Korean Society for Molecular and Cellular Biology. All rights reserved.

(c) This is an open-access article distributed under the terms of the Creative Commons Attribution-NonCommercial-ShareAlike 3.0 Unported License. To view a copy of this license, visit http://creativecommons.org/licenses/by-nc-sa/3.0/. 
al., 2010). Furthermore, analysis of U87-MG laser-capture micro dissected cells in tumor-bearing mice indicated that expression of miR-146b-5p is inversely correlated with distance from the tumor core (Katakowski et al., 2010). miR-335 activates the p53 tumor suppressor pathway to limit cell proliferation and neoplastic cell transformation (Scarola et al., 2010). miR335 is increased by CREB and ATM-dependent miR-335 targets CtIP and modulates the DNA damage response (Martin et al., 2013). miR-335 targets Bcl-w and negatively regulates invasion potential of ovarian cancer cells (Cao et al., 2013). In addition, miR-335 inhibits proliferation and migration of human mesenchymal stem cells by targeting RUNX2 (Tome et al, 2011). miR-335 is involved in regulating target genes in several oncogenic signal-pathways such as p53, MAPK, TGF- $\beta$, Wnt, ERbB, mTOR, Toll-like receptor and focal adhesion (Yan et al., 2012). Upregulation of miR-335 simultaneously suppresses the invasiveness and promote apoptosis of A549 and H1299 lung cancer cells by targeting Bcl-w and SP1 (Wang et al., 2013). miR-335 level is decreased in hepatocellular carcinoma (Dohi et al., 2013) suggestive of its role as a tumor suppressor. The tumor suppressor role of miR-335 has been reported in prostate cancer (Xiong et al., 2013). miR-335 is reportedly down-regulated in drug-resistant ovarian cancer cell lines indicative of its potential role in anti-cancer drug-resistance (Sorrentino et al., 2008). The identification of miRNAs that regulate the expression of HDAC3 is necessary for a better understanding of the mechanism of anti-cancer drug-sensitivity conferred by HDAC3.

In this study, we showed that the decreased expression of HDAC3 in anti-cancer drug-resistant cancer cell lines results from the ubiquitination of HDAC3 by SIAH2. Furthermore, we showed that miR-335 targets $\mathrm{SIAH} 2$ to increase the expression of HDAC3 and miR-335 prevents $\mathrm{SIAH} 2$ from inducing ubiquitnation of HDAC3. The overexpression of SIAH2 induced anti-cancer drug-resistance associated with its effect on the expression and ubiquitination of HDAC3. Thus, the miR-335SIAH2-HDAC3 axis is a potential target for the development of anti-cancer therapeutics.

\section{MATERIALS AND METHODS}

\section{Materials}

Anti mouse and anti rabbit IgG-horse radish peroxidase conjugate antibodies were purchased from Pierce Company. An ECL (enhanced chemiluminiscence) kit was purchased from Amersham. Lipofectamin, Plus ${ }^{\mathrm{TM}}$ reagent, Trizol and reverse trancriptase (Superscript II RT) were purchased from Invitrogen (USA). Bioneer (Korea) synthesized all primers and miRinhibitor used in this study. 3-(4, 5-dimethylthiazol-2-yl)-2, 5diphenyltetrazolium bromide (MTT) and all other chemicals used in this study were purchased from Sigma. Anchorageindependent growth assays kit was purchased from Millipore. Annexin V-FITC kit for the detection of apoptosis was purchased from Biovision. Transwell chamber system with 8- $\mu \mathrm{m}$ pore polycarbonate filter inserts for the determination of invasion potential was purchased from CoSTAR (USA). Quickchange site-directed mutagenesis kit was purchased from Stratagene. miRNA array was purchased from Signosis Company. SiRNA construction kit, mirVana miRNA isolation kit and SYBR Green qRT-PCR kit were purchased from Ambion (USA) $\mathrm{qScript}^{\mathrm{TM}}$ reverse transcriptase was purchased from Quanta Biogenesis. A-Plus Poly $(A)$ Polymerase Tailing Kit was purchased from Cell Script. SYBR PCR Master Mix was purchased from Applied Bosystems.
Cell lines and cell culture

Cancer cell lines used in this study were cultured in Dulbecco's modified minimal essential medium (DMEM; Gibco, USA) supplemented with heat-inactivated $10 \%$ fetal bovine serum (FBS, Gibco) and antibiotics at $37^{\circ} \mathrm{C}$ in a humidified incubator with a mixture of $95 \%$ air and $5 \% \mathrm{CO}_{2}$. Cancer cell lines made resistant to anti-cancer drugs $\left(\mathrm{SNU} 387^{\mathrm{R}}\right.$, Malme3M $\mathrm{M}^{\mathrm{R}}, \mathrm{SNU} 387^{\mathrm{R}-}$ taxol, Malme $3 \mathrm{M}^{\mathrm{R} \text {-Taxol }}$, SNU387 ${ }^{\mathrm{R} \text {-Vinblastine }}$ ) were established by stepwise addition of the respective drug. SNU $387^{\mathrm{R}}$ and Malme $3 \mathrm{M}^{R}$ cells are cancer cell lines made resistant to celastrol. Cells surviving drug treatment (attached fraction) were obtained and used throughout this study. SNU $387^{R}$ or Malme $3 M^{R}$ cells that stably express HDAC3 S424A-Flag or HDAC3-Flag were selected by $\mathrm{G} 418(400 \mu \mathrm{g} / \mathrm{ml})$. Malme3M $\mathrm{M}^{\mathrm{R}-\mathrm{miR}-335}$ cells were also selected by $\mathrm{G} 418$.

Western blot analysis

Western blot analysis, immunoprecipitation and cellular fractionation were performed according to the standard procedures (Kim et al., 2014). For analysis of proteins from tumor tissues, frozen samples were grounded to a fine powder using a mortar and pestle over liquid nitrogen. Proteins were solubilized in RIPA buffer containing protease inhibitors, and insoluble material removed by centrifugation.

\section{Cell viability determination}

Viable cell number counting was carried out by trypan blue exclusion assays.

\section{Annexin V-FITC staining}

Apoptosis determination was carried out by using annexin VFITC. Ten thousand cells were counted for three independent experiments.

\section{In vivo drug resistance and tumorigenic potential}

Athymic nude mice (BALB/c nu/ nu, 5-6-week-old females) were obtained from Orient Bio Inc. (Korea) and were maintained in a laminar air-flow cabinet under aseptic conditions. Each cancer cells $\left(1 \times 10^{6}\right)$ were injected subcutaneously into the dorsal flank area of the mice. Tumor volume was determined by direct measurement with calipers and calculated by the following formula: length $\times$ width $\times$ height $\times 0.5$. Following the establishment of sizeable tumor, celastrol $(1 \mathrm{mg} / \mathrm{kg})$ or taxol $(1 \mathrm{mg} / \mathrm{kg}$ ) was administered via tail vein. Tumor volume was measured as describe above. All animal experiments were approved by the Institutional Animal Care and Use Committee of Kangwon National University (KW-140707-1).

\section{Anchorage-independent growth assay}

The assays were done in 96-well plates, and the plates were incubated at $37^{\circ} \mathrm{C}$ for $21-28$ days. Anchorage-independent growth was evaluated by using the cell stain solution. Stained colonies were counted using a microscope and intensity of staining was quantified by measuring absorbance at $490 \mathrm{~nm}$.

\section{Chemo invasion assays}

The invasive potential was determined by using a transwell chamber system with 8- $\mu \mathrm{m}$ pore polycarbonate filter inserts. The lower and upper sides of the filter were coated with gelatin and Matrigel, respectively. Trypsinized cells $\left(5 \times 0^{3}\right)$ in the serum-free RPMI 1640 medium containing $0.1 \%$ bovine serum albumin were added to each upper chamber of the transwell. RPMI 1640 medium supplemented with $10 \%$ fetal bovine serum was placed in the lower chamber, and cells were incubated 
at $37^{\circ} \mathrm{C}$ for $16 \mathrm{~h}$. The cells were fixed with methanol, and the invaded cells were stained and counted. Results were analyzed for statistical significance using the Student's $t$ test. Differences were considered significant when $\mathrm{p}<0.05$.

\section{Wound migration assays}

Cells were plated overnight to achieve a confluent layer in 24well plates. A scratch was made on the cell layer with a micropipette tip, and cultures were washed twice with serum-free medium. Cells were then transfected with the construct of interest. Wound healing was visualized by comparing photographs taken at the time of transfection and $48 \mathrm{~h}$ later.

RNA extraction and quantitative real-time PCR miRNA was extended by a poly $(A)$ tailing reaction using the APlus Poly(A) Polymerase Tailing Kit. cDNA was synthesized from miRNA with poly $(A)$ tail using a poly $(T)$ adaptor primer and $\mathrm{qScript}^{\mathrm{TM}}$ reverse transcriptase (Quanta Biogenesis). Expression levels of miR-335 was quantified with SYBR Green qRTPCR kit using a miRNA-specific forward primer and a universal poly $(T)$ adaptor reverse primer. The expression of miR-335 was defined based on the threshold $(\mathrm{Ct})$, and relative expression levels were calculates as $2^{-[(C t \text { of miR-335)-(Ct of U6)] }}$ after normalization with reference to expression of U6 small nuclear RNA For detection of HDAC3 RNA level, Total RNA was isolated using Trizol and $1 \mu \mathrm{g}$ of total RNA was used to synthesize complementary DNA using random primers and reverse transcriptase (SuperScript II RT). For quantitative real-time PCR, SYBR PCR Master Mix was used in a CFX96 Real-Time System thermocycler (Biorad). The mRNA level for HDAC3 was normalized to the $\beta$-actin value and relative quantification was determined using the $\triangle \mathrm{C}$ model presented by PE Applied Biosystems (Perkin Elmer, USA).

HDAC 3 constructs

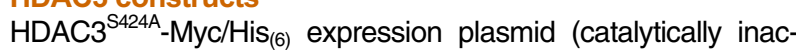
tive HDAC3 mutant) was derived from pFlag-HDAC3 with the Quick-change site-directed mutagenesis kit. HDAC3 serial deletion mutant constructs were made by cloning various PCRamplified HDAC3 fragments into pcDNA3.1-Myc/His vector.

\section{miR-335 and pGL3-3'UTR-SIAH2 construct}

To generate miR-335 expression vector, a 351bp genomic fragment encompassing primary miR-335 gene was PCR amplified and cloned into BamHI/Xhol site of pcDNA3.1 vector. To generate pGL3-3'UTR-SIAH2 construct, 250 bp human SIAH2 gene segment encompassing $3^{\prime}$ UTR was PCR amplified and subcloned into Xbal site of pGL3 luciferase plasmid. Mutant pGL3-3'UTR-SIAH2 construct was made with the Quickchange site-directed mutagenesis kit (Stratagene). Luciferase activity assay was performed according to the instruction manual (Promega Company).

miRNA analyses

miRNA array analysis to identify miRNAs that are related with anti cancer drug-resistance was performed according to the instruction manual provided by manufactures (Signosis Company). Genes that contain the miR-binding site (s) in the UTR were obtained using the TargetScan program.

\section{Oligonucleotide transfections}

For miR-335 knockdown, cells were transfected with $100 \mathrm{nM}$ of oligonucleotide with Lipofectamine 2000 . The sequences used were: 5'-ACAUUUUUCGUUAUUGCUCUUGA-3' (miR-335 in- hibitor oligonucleotide); and 5'-UUGUACUACACAAAAGUACUG-3' (control inhibitor).

\section{Statistical analysis}

Data were analyzed and graphed using the GraphPad Prism statistics program (GraphPad Software).

Results are presented as mean \pm S.E. Statistical analysis was performed using Student's $t$ tests with differences between means considered significant when $p$ was $<0.05$.

\section{RESULTS}

The expression of HDAC3 is under proteasomal regulation The expression level of HDAC3 is lower in anti-cancer drugresistant cancer cell lines than in anti-cancer drug-sensitive cancer cell lines (Kim et al., 2014). We therefore investigated the mechanism of expression regulation of HDAC3. In most of the anti-cancer drug-resistant cancer cell lines, the expression level of HDAC3 did not show difference from anti-cancer drugsensitive cancer cell lines (data not shown). We therefore examined the possibility of proteasomal degradation of HDAC3 in anti-cancer drug-resistant cancer cell lines. MG132, an inhibitor of proteasomal degradation, restored the expression of HDAC3 in anti-cancer drug-resistant cancer cell lines such as SNU387 ${ }^{\mathrm{R}}$,

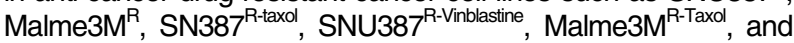
WM266-4 cells (Fig. 1A). This suggests that the expression level of HDAC3 may be under proteasomal regulation. Celastrol and taxol decreased the expression of HDAC3 while increasing the expression of SIAH2 in Malme3M cells (Fig. 1B). SIAH2, E3 ubiquitin ligase, induces proteasomal degradation of target proteins (Christian et al., 2011) suggestive of its regulatory role in the response to anti-cancer drugs. Because HDAC3 expression level is regulated by proteasome-dependent ubiquitination, we hypothesized that the expression of E3 ubiquitin ligases, including SIAHs are increased in cancer cell lines resistant to anti-cancer drugs. The E2 ubiquitin conjugase UBCH8 (ubiquitin conjugating enzyme [human] 8) cooperates with the E3 ubiquitin ligases SIAH1 and SIAH2 (seven in absentia homolog $1 / 2$ ) to mediate the proteasomal degradation of oncoproteins (Pietschmann et al., 2012). SIAH2 mediates HDAC3 degradation, and Ski protein exerts a negative effect on SIAH2mediated HDAC3 degradation by interaction with SIAH2 (Zhao et al., 2010). Ski is necessary for proper chromosome segregation and interacts with aurora kinase $A$ at the centrosome (Mosquera et al., 2011). HDAC3 serves as a substrate of Src (Longworth and Laimins, 2006) and Src activates SIAH2 E3 ubiquitin ligase activity (Sarkar et al., 2012). These reports imply a role for SIAH2 in the regulation of HDAC3 expression. $\mathrm{SIAH} 1$ and SIAH2 showed relatively higher expression in anticancer drug-resistant cancer cell lines vs. anti-cancer drugsensitive cancer cell lines (Fig. 1C). The down-regulation of SIAH2 increased the expression of HDAC3 (Fig. 1D), suggesting that $\mathrm{SIAH} 2$ may act as a negative regulator of HDAC3. Taken together, these results suggested that proteasomal degradation is responsible for the decreased expression of HDAC3 in anti-cancer drug-resistant cancer cells.

$\mathrm{SIAH} 2$ is responsible for the ubiquitination of HDAC3 Because expression level of HDAC3 is regulated by proteasomal degradation regulation, we examined ubiquitination of HDAC3 in anti-cancer drug-resistant cancer cells. Anti-cancer drug-resistant cancer cells, such as SNU387 $7^{\mathrm{R}}$, SNU387 ${ }^{\mathrm{R} \text {-taxol }}, \mathrm{SNU} 387^{\mathrm{R}-\text { Vinblastne }}$ Malme3M ${ }^{\mathrm{R}}$ and Malme $3 \mathrm{M}^{\mathrm{R} \text {-taxol }}$, showed ubiquitination of HDAC3 (Fig. 2A). The down-regulation of SIAH2 prevented the ubi- 


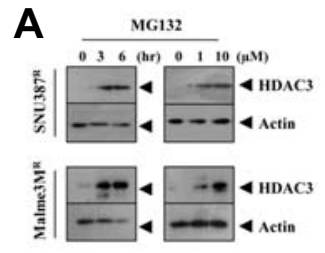

B
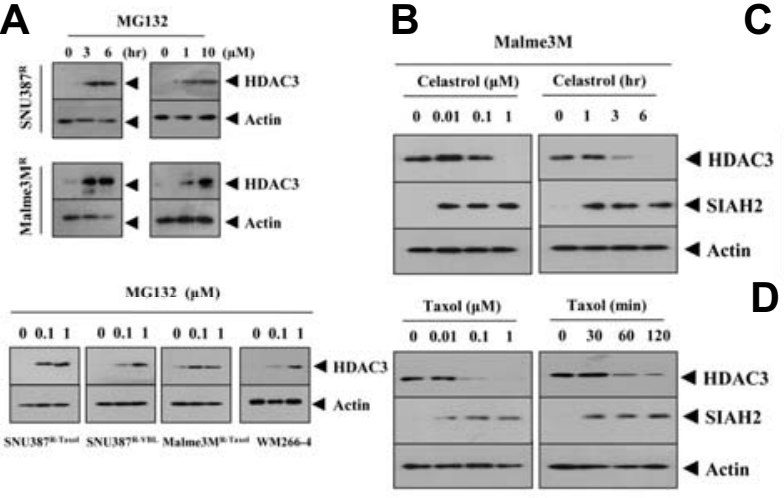

D

SNU387 Malme3M ${ }^{R}$ IYM266-4

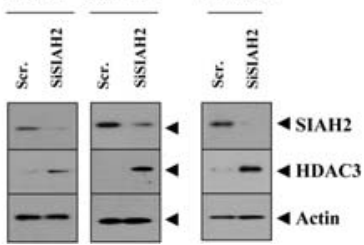

Fig. 1. HDAC3 is subjected to ubiquitin-dependent proteasomal degradation. (A) SNU387 ${ }^{\mathrm{R}}$ or Malme $3 \mathrm{M}^{\mathrm{R}}$ cells were treated with various concentrations of MG132 for $6 \mathrm{~h}$ or $1 \mu \mathrm{M}$ MG132 for various time intervals. SNU $387^{\text {R-Taxol, }}$ SNU387 ${ }^{\text {R-Vinblastine, }}$, Malme $3 \mathrm{M}^{\text {R-Taxol }}$ or WM266-4 cells were also treated with various concentration of MG132 for 6 h. (B) Malme3M cells treated with celastrol or taxol as indicated were subjected to Western blot analysis. (C) Cell lysates isolated from the indicated cancer cells were subjected to Western blot analysis. (D) The indicated cancer cells were transiently transfected with $10 \mathrm{nM}$ of the indicated

siRNA. At $48 \mathrm{~h}$ after transfection, cell lysates were isolated and subjected to Western blot analysis. Scr. denotes scrambled siRNA.

A

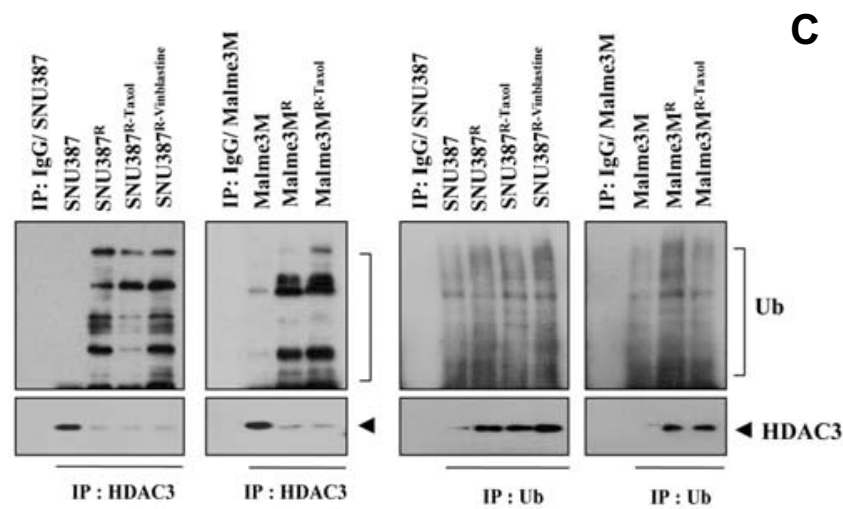

B

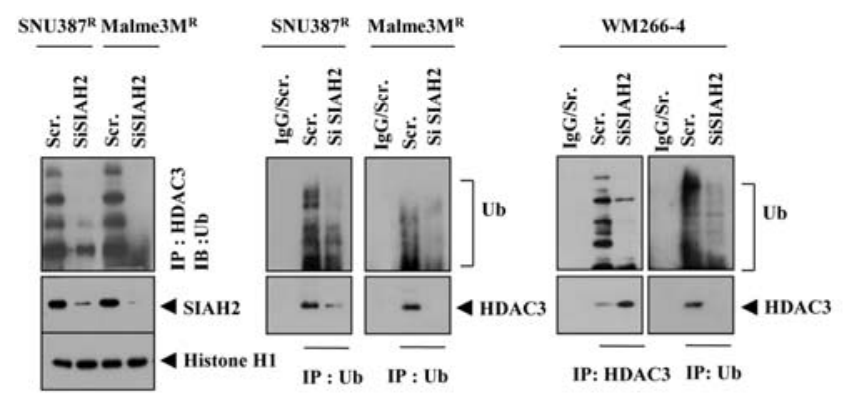

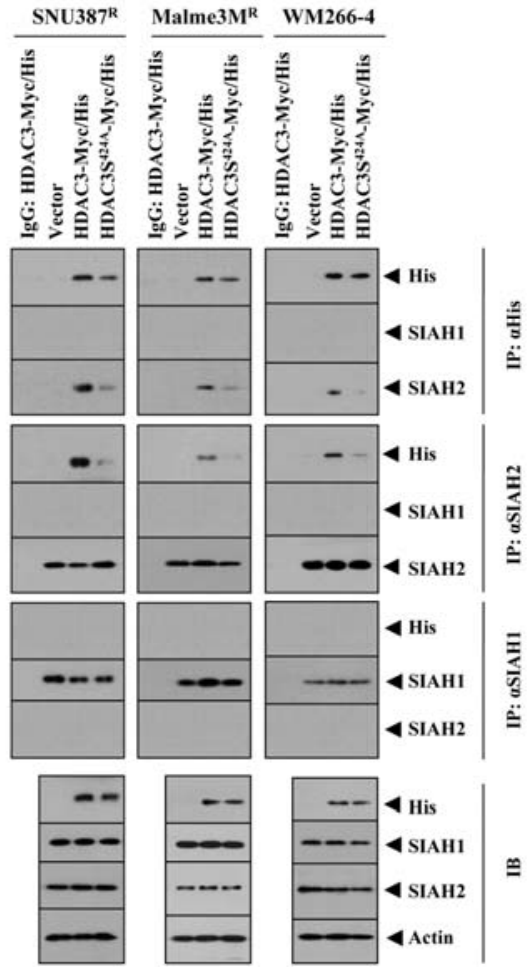

Fig. 2. SIAH2 is responsible for the ubiqutination of HDAC3. (A) Nuclear extracts from each cell line were immunoprecipitated with the indicated antibody $(2 \mu \mathrm{g} / \mathrm{ml})$, followed by Western blot. Nuclear extracts from SNU387 or Malme3M cells were also immunoprecipitated with isotypematched anti-lgG antibody $(2 \mu \mathrm{g} / \mathrm{ml})$, followed by Western blot. Ub denotes ubiquitin. (B) At $48 \mathrm{~h}$ after transfection, nuclear extracts were immunoprecipitated with the indicated antibody $(2 \mu \mathrm{g} / \mathrm{ml})$, followed by Western blot. Nuclear extracts were also subjected to Western blot. Nuclear extracts from SNU387 ${ }^{\mathrm{R}}$, Malme3M $\mathrm{M}^{\mathrm{R}}$ or WM266-4 cells transfected with Scr. were also immunoprecipitated with anti-lgG antibody (2 $\mu \mathrm{g} / \mathrm{ml}$ ), followed by Western blot. (C) The indicated cancer cells were transiently transfected with $1 \mu \mathrm{g}$ of the indicated construct. At $48 \mathrm{~h}$ after transfection, cell lysates were immunoprecipitated with the indicated antibody $(2 \mu \mathrm{g} / \mathrm{ml})$, followed by Western blot analysis. Cell lysates were also subjected to Western blot analysis.

quitination of HDAC3 in anti-cancer drug-resistant cancer cell lines such as SNU387 ${ }^{\mathrm{R}}$, Malme3M ${ }^{\mathrm{R}}$ and WM266-4 cells (Fig. 2B). Because SIAH2 regulated the expression of HDAC3 by ubiquitination (Fig. 2B), we examined the possibility of interac- tion between HDAC3 and SIAHs. Wild type HDAC3, but not mutant HDAC3 (HDAC3 ${ }^{\text {S424A }}$ ), showed an interaction with SIAH2, but not with SIAH1 (Fig. 2C), suggesting that SIAH2, but not SIAH1, may target HDAC3 for ubiquitination. Wild type 
miR-335/SIAH2/HDAC3 Axis in the Response to Anti-Cancer Drug

Youngmi Kim et al.

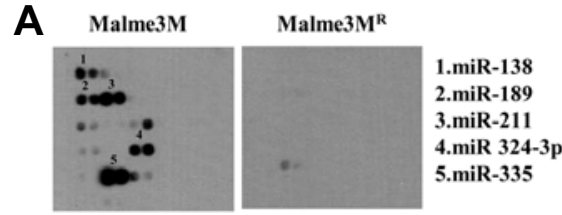

B

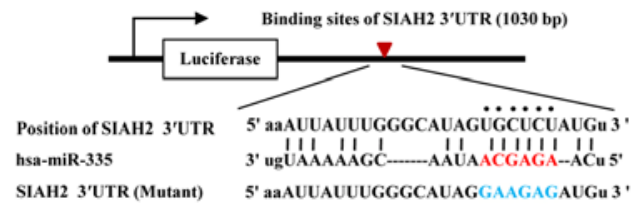

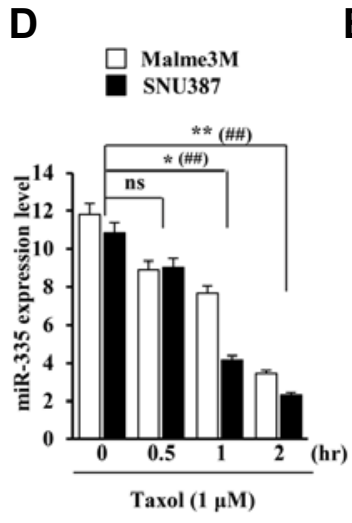
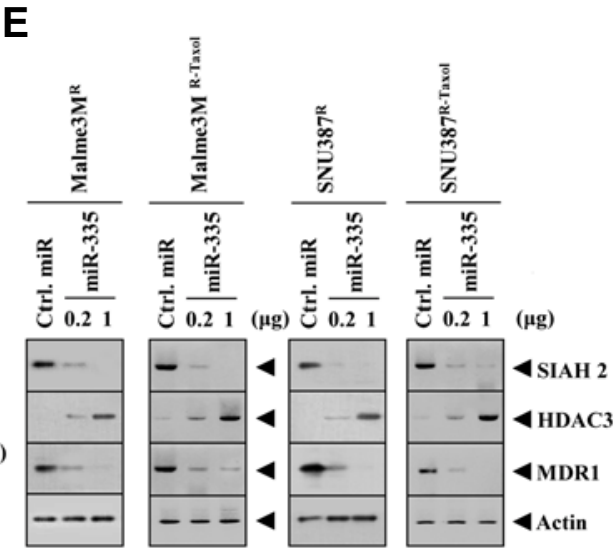

$\mathbf{F}$

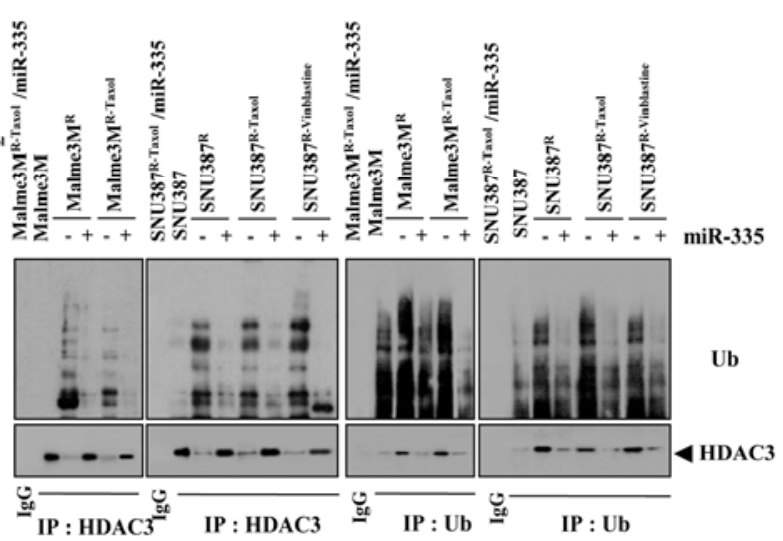

Fig. 3. SIAH2 targets HDAC3 for ubiquitination. (A) miRNA array analysis employing the indicated cancer cell lines was performed as described. (B) Potential binding sites of miR-335 in the 3'-UTR of SIAH2. (C) Wild type or mutant pGL3-SIAH2-3'UTR reporter plasmid with the luciferase coding sequence fused to the wild type or mutant $3^{\prime} \mathrm{UTR}$ of SIAH2 was cotransfected into each cell line with pcDNA3.1-miR-335 (1 $\mu \mathrm{g})$ or pcDNA $3.1(1 \mu \mathrm{g})$. Relative luciferase activity $=\left(\mathrm{S}_{\text {lud }} / \mathrm{C}_{\text {luc }}\right)$. $\mathrm{S}_{\text {luc }}$, RLUs of luciferase activity in the pcDNA3.1-miR-335-tansfected cell line. $\mathrm{C}_{\text {luc }}$, RLUs of luciferase activity in the pcDNA3.1-tansfected cell line. Each value represents an average of 3 independent experiments. The asterisk $\left(^{*}\right)$ indicates the statistical difference between pcDNA 3.1 control vector and miR-335 transfections. Luciferase activity assays were performed as described. (D) The indicated cancer cells were treated with taxol $(1 \mu \mathrm{M})$ for various time intervals. miRNAs isolated at each time point were subjected to qRT-PCR analysis. (E) The indicated cancer cell line was transfected with pcDNA 3.1 vector $(1 \mu \mathrm{g})$ or pcDNA3.1-miR335 construct $(1 \mu \mathrm{g})$. At $48 \mathrm{~h}$ after transfection, cell lysates were prepared and subjected to Western blot analysis. $(F)$ The indicated cell line was transfected with pcDNA 3.1 vector $(1 \mu \mathrm{g})$ or pcDNA3.1-miR-335 construct $(1 \mu \mathrm{g})$. At $48 \mathrm{~h}$ after transfection, cell lysates were immunoprecipitated with anti-HDAC3 antibody $(2 \mathrm{ug} / \mathrm{ml})$ or anti-Ub antibody $(2 \mu \mathrm{g} / \mathrm{ml})$, followed by Western blot. Cell lysates prepared from SNU387 ${ }^{\mathrm{R} \text {-Taxol }}$ or Malme3M ${ }^{\mathrm{R} \text {-Taxol }}$ cells transfected with pcDNA3.1-miR-335 construct were also immunoprecipitated with isotype-matched anti$\operatorname{lgG}$ antibody $(2 \mu \mathrm{g} / \mathrm{ml})$, followed by Western blot. Cell lysates isolated from Malme3M or SNU387 cells were immuoprecipitated with the indicated antibody, followed by Western blot analysis.

HDAC3 that contains nuclear localization signal sequences (313-428 of HDAC3) shows localization into the nucleus (Park et al., 2014a). However, HDAC3 ${ }^{\text {S424A }}$ does not show localization into the nucleus (Park et al., 2014b). Taken together, these results suggested that SIAH2 might target HDAC3 for ubiquitina- tion to decrease the expression of HDAC3.

miR-335 targets SIAH2 and increases the expression of HDAC3 by inhibiting ubiquitination of HDAC3

We performed microRNA array (miRNA array) experiments in an effort to identify factor(s) that would affect the expression of HDAC3 and SIAH2. We found that several microRNAs were decreased in the Malme3M ${ }^{R}$ cells (Fig. 3A). These miRNAs may regulate expression of $\mathrm{SIAH} 2$, which in turn could affect response to anti-cancer drugs by regulating the expression of
HDAC3. Targetscan analysis predicted the binding of miR-335 to the $3^{\prime}$-UTR of SIAH2 (Fig. 3B). miR-335 decreased the luciferase activity of wild type pGL3-3'UTR-SIAH2, but not mutant pGL3-3'UTR-SIAH2, in various anti-cancer drug-resistant cancer cell lines (Fig. $3 C$ ), suggesting that miR-335 directly targets $\mathrm{SIAH} 2$. Taxol decreased expression of miR-335 in Malme3M and SNU387 cells (Fig. 3D), suggesting the involvement of miR-335 in regulating the response to anti-cancer drugs. miR335 decreased the expression of SIAH2 and MDR1 while increasing expression of HDAC3 in cancer cell lines that were made resistant to anti-cancer drugs (Fig. $3 E$ ). However, miR335 did not affect the expression of SIAH1 (data not shown). miR-335 inhibited ubiquitination of HDAC3 (Fig. 3F). Taken together, these results suggest that miR-335 increases the expression of HDAC3 by targeting $\mathrm{SIAH} 2$. 

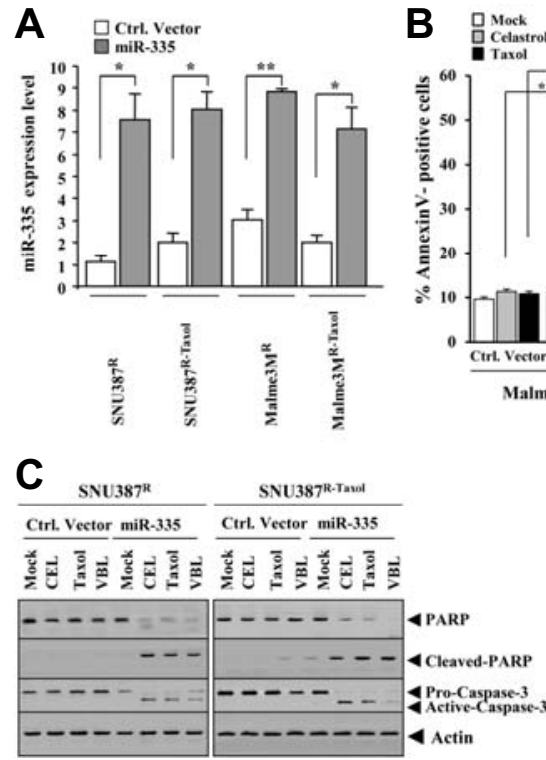
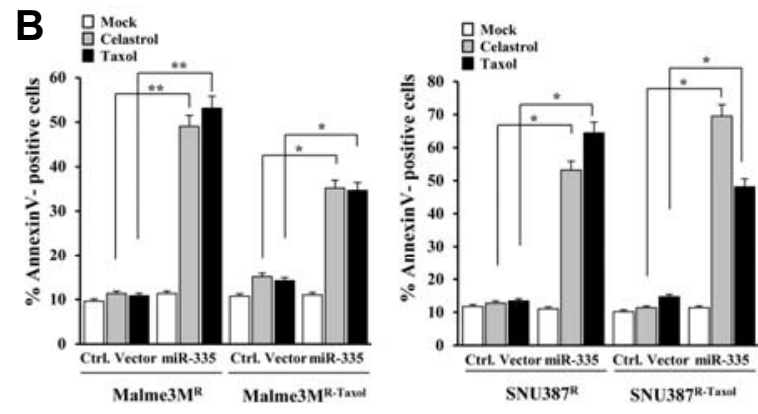

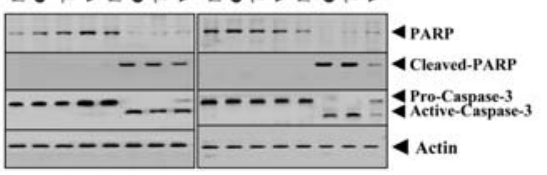

Fig. 4. miR-335 confers sensitivity to anti-cancer drugs. (A) The indicated cancer cell line was transiently transfected with pcDNA $3.1(1 \mu \mathrm{g})$ or pcDNA 3.1-miR-335 construct $(1 \mu \mathrm{g})$. At $48 \mathrm{~h}$ after transfection, expression level of miR-335 was determined by quantitative real-time PCR. The asterisk $\left(^{*}\right)$ indicates statistical difference $(p$ $<0.05)$ between control vector (pcDNA 3.1) and miR-335 transfections. ${ }^{*} p<0.05$; ${ }^{* *} p<0.005$. (B) The indicated cell line was transiently transfected with pcDNA $3.1(1 \mu \mathrm{g})$ or pcDNA 3.1-miR-335 construct $(1 \mu \mathrm{g})$. At $24 \mathrm{~h}$ after transfection, the indicated cancer cell line was treated with or without various concentrations of the indicated drug for $24 \mathrm{~h}$, followed by annexin V-FITC staining. ${ }^{*} p<0.05$; ${ }^{* *} p$ $<0.005$. (C) The indicated cell line was transiently transfected with pcDNA 3.1 $(1 \mu \mathrm{g})$ or pcDNA 3.1-miR-335 construct $(1 \mu \mathrm{g})$. At $24 \mathrm{~h}$ after transfection, the indicated cell line was treated with or without celastrol $(1 \mu \mathrm{M})$, taxol $(1 \mu \mathrm{M})$ or vinblastine $(100 \mathrm{nM})$ for $24 \mathrm{~h}$. Cell lysates were subjected to Western blot analysis.
A
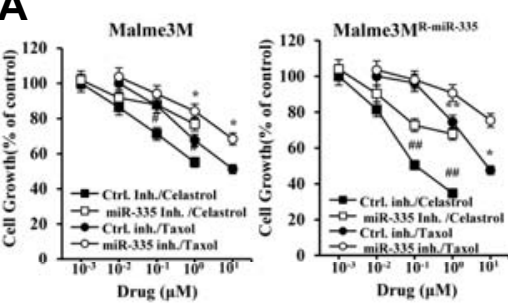

C

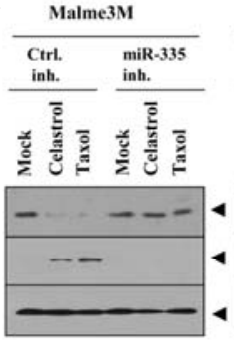

Malme3MR-mir-nes
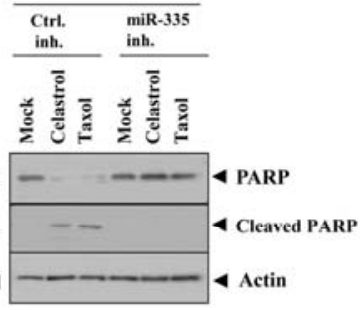

B
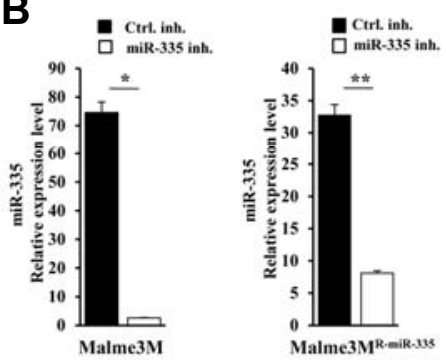

D

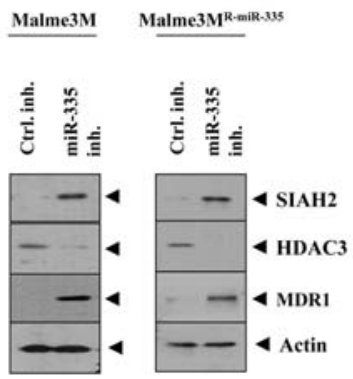

Fig. 5. miR-335 inhibitor induces resistance to anti-cancer drugs. (A) The indicated cancer cells were transiently transfected with control inhibitor (10 nM) or miR-335 inhibitor (10 nM). At $24 \mathrm{~h}$ after transfection, cells were treated with various concentrations of celastrol or taxol for $24 \mathrm{~h} .{ }^{* *},{ }^{\# \#} ; \mathrm{p}<0.005$; ${ }^{*},{ }^{\#} \mathrm{p}<$ 0.05 . $P$ value was determined in comparison with value obtained from each respective control. Data is expressed as a mean \pm SD. Each value represents an average of 3 independent experiments. (B) miR-335 expression in each cancer cell line transfected with control inhibitor (10 $\mathrm{nM})$ or miR-335 inhibitor (10 nM). ${ }^{*} p<0.05 ;{ }^{* *} p<0.005$. (C) The indicated cancer cells were transiently transfected with control inhibitor or miR335 inhibitor. At $24 \mathrm{~h}$ after transfection, cells were treated with celastrol $(1 \mu \mathrm{M})$ or taxol $(1 \mu \mathrm{M})$, followed by Western blot analysis. (D) The indicated cancer cells were transiently transfected with control inhibitor $(10 \mathrm{nM})$ or miR-335 inhibitor $(10 \mathrm{nM})$. At $48 \mathrm{~h}$ after transfection, Western blot analysis was performed.

miR-335 regulates the response to anti-cancer drugs

Next, we examined whether miR-335 would confer sensitivity to anti-cancer drugs. For this, miR-335 was transfected into various anti-cancer drug-resistant cancer cell lines such as SNU $387^{\mathrm{R}}$

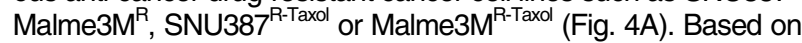
annexin V-FITC staining, miR-335 enhanced the sensitivity of

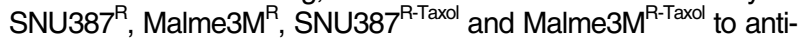
cancer drugs (Fig. 4B). miR-335 enhanced cleavages of PARP

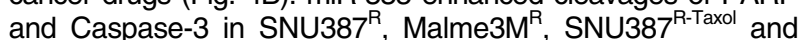
Malme $3 \mathrm{M}^{\mathrm{R} \text {-Taxol }}$ in response to anti-cancer drugs (Fig. $4 \mathrm{C}$ ). We next examined the effect of miR-335 inhibitor on the response to anti-cancer drugs. miR-335 inhibitor induced resistance to anti-cancer drugs in anti-cancer drug-sensitive cancer cell lines such as Malme3M and Malme3M $\mathrm{M}^{\mathrm{R}-\mathrm{miR}-335}$ cells (Fig. 5A). miR335 inhibitor decreased the expression of miR-335 in Malme3M and Malme3M ${ }^{\mathrm{R}-\mathrm{miR}-335}$ cells (Fig. 5B). miR-335 inhibitor prevented cleavage of PARP by anti-cancer drugs in Malme3M and Malme $3 \mathrm{M}^{\mathrm{R}-\mathrm{miR}-335}$ cells (Fig. 5C). miR-335 inhibitor induced the expression of SIAH2 and MDR1 while decreasing the expression of HDAC3 in Malme3M and Malme $3 \mathrm{M}^{\mathrm{R}-\mathrm{miR}-335}$ cells (Fig. 

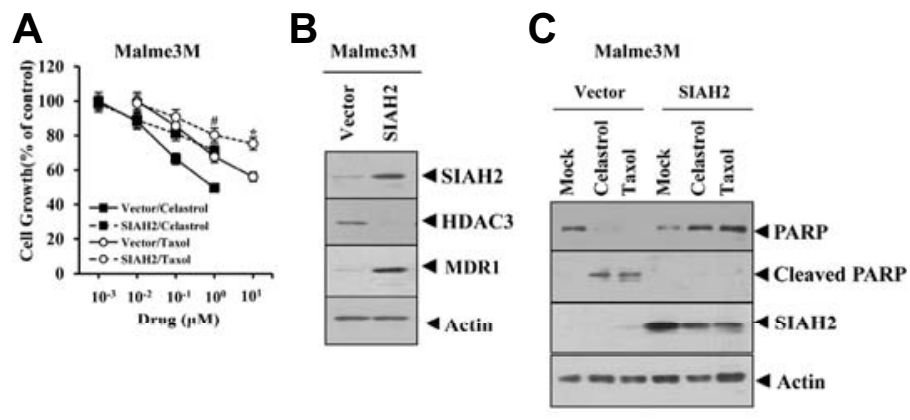

\section{D}

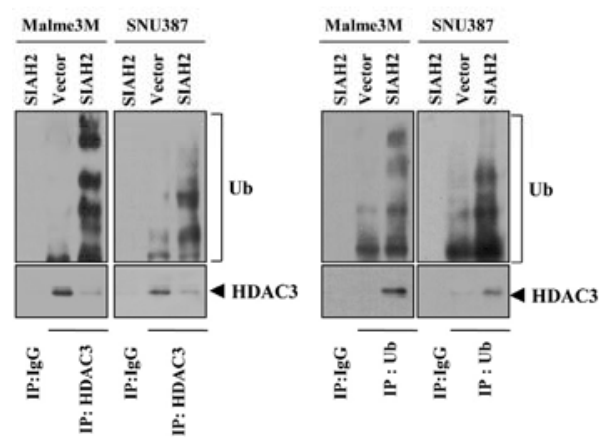

Fig. 6. SIAH2 confers resistance to anti-cancer drugs by regulating the expression and ubiquitination of HDAC3. (A) Malme3M cells were transfected with the control vector (1 $\mu \mathrm{g})$ or SIAH2 cDNA $(1 \mu \mathrm{g})$. The next day, cells were treated with various concentrations of the indicated drug for $24 \mathrm{~h}$. *, $p<0.05$. $P$ value was determined in comparison with value obtained from Malme3M cells transfected with control vector. (B) At $48 \mathrm{~h}$ after transfection with control vector $(1 \mu \mathrm{g})$ or SIAH2 cDNA $(1 \mu \mathrm{g})$, Western blot was performed. (C) Malme3M cells were transfected with control vector $(1 \mu \mathrm{g})$ or SIAH2 cDNA $(1 \mu \mathrm{g})$. The next day, cells were treated with celastrol $(1 \mu \mathrm{M})$ or taxol $(1 \mu \mathrm{M})$ for $24 \mathrm{~h}$, followed by Western blot. (D) The indicated cancer cells were transiently transfected with control vector $(1 \mu \mathrm{g})$ or SIAH2 cDNA $(1 \mu \mathrm{g})$. At $48 \mathrm{~h}$ after transfection, cell lysates were immunoprecipitated with the indicated antibody $(2 \mu \mathrm{g} / \mathrm{ml})$, followed by Western blot analysis.
A

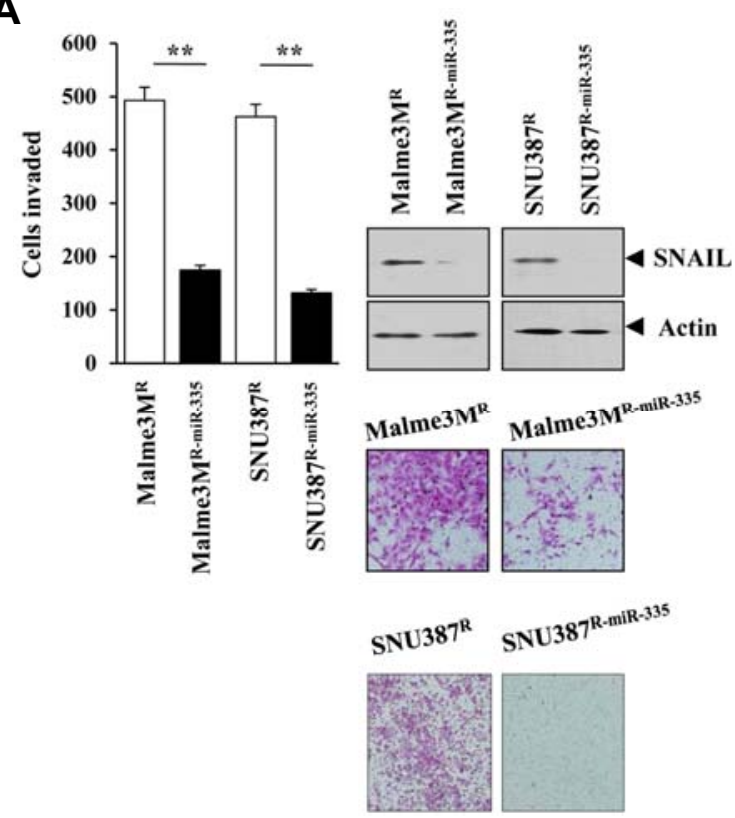

B

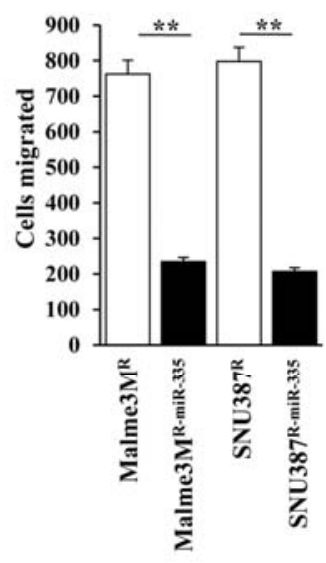

Ohr

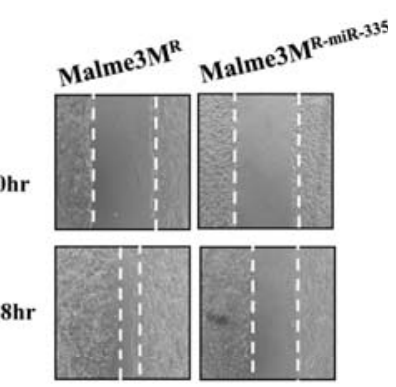

Fig. 7. miR-335 regulates the invasion and migration potential of cancer cells. (A) The indicated cancer cell lines were subjected to invasion assays. Cell lysates isolated from the indicated cell lines were subjected to Western blot analysis. ${ }^{\star *} p<0.005$. (B) The indicated cancer cell lines were subjected to wound migration assays. Movement of cells into wound was shown for the indicated cancer cell lines at 0 and $48 \mathrm{~h}$ post scratch (40X). Data were the means of 3 independent experiments and the bars represent SD of the mean. The broken lines indicate the boundary lines of scratch. ${ }^{\star \star} p<0.005$.

5D). Taken together, these results suggested that miR-335 regulates the response to anti-cancer drugs in association with its effect on SIAH2 and HDAC3 expression.
SIAH2 confers resistance to anti-cancer drugs by regulating the expression and ubiquitination of HDAC3

Because SIAH2 regulates the expression of HDAC3 (Fig. 1D), 
A

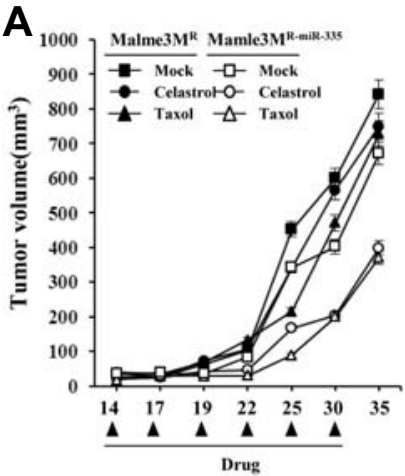

C
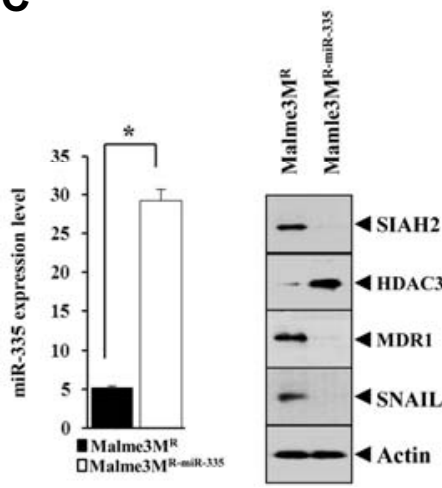

B

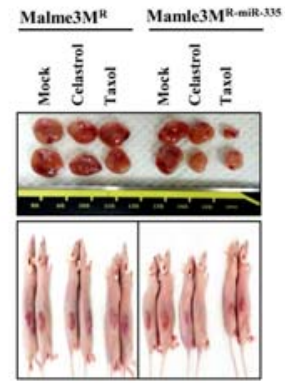

D

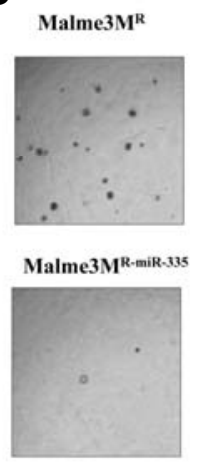

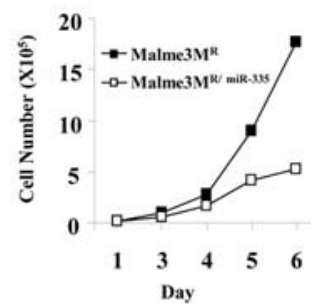

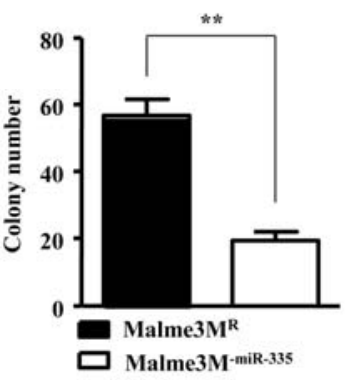

Fig. 8. miR-335 regulates the tumorigenic potential and growth potential of cancer cells. (A) Malme $3 \mathrm{M}^{\mathrm{R}}$ cells $\left(1 \times 10^{6}\right)$ or Malme3M $\mathrm{M}^{\mathrm{R}-\mathrm{miR}-335}$ cells $\left(1 \times 10^{6}\right)$ were injected into the dorsal flank area of athymic nude mouse. Celastrol $(1 \mathrm{mg} /$ $\mathrm{kg})$ or taxol $(1 \mathrm{mg} / \mathrm{kg})$ was injected into each nude mouse after the tumor reached a certain size. Tumor volume was measured on the same day as injection of inhibitor (left panel). Five mice were used for the injection of each cell line. Each value represents an average obtained from five mice of each group. Data are expressed as mean \pm SD. (B) the growth rate of the indicated cell line was measured by trypan blue exclusion assay. (C) miRNA isolated from each tumor tissue was subjected to quantitative real-time PCR to measure the expression of miR-335 (left panel). Western blot of tumor lysates was also performed (right panel). ${ }^{*} p<0.05$. (D) Anchorage-independent growth assays employing Malme $3 \mathrm{M}^{\mathrm{R}}$ and Malme $3 \mathrm{M}^{\mathrm{R}}$ cells were performed. ${ }^{* *} p<0.005$. we examined the effect of SIAH2 on the response to anticancer drugs. Over expression of SIAH2 conferred resistance to anti-cancer drugs in Malme3M cells (Fig. 6A). SIAH2 decreased expression of HDAC3 while increasing the expression of MDR1 (Fig. 6B). SIAH2 prevented cleavage of PARP by anti-cancer drugs in Malme3M cells (Fig. 6C). SIAH2 induced ubiquitination of HDAC3 (Fig. 6D). Taken together, these results suggested that $\mathrm{SIAH} 2$ targets HDAC3 for ubiquitination to confer resistance to anti-cancer drugs.

\section{miR-335 regulates the invasion and migration of cancer} cells

The invasion and migration potential of cancer cells are associated with the response to anti-cancer drugs (Kim et al., 2014). We therefore examined the effect of miR-335 on the invasion and migration of cancer cells. SNU $387^{\mathrm{R}-\mathrm{miR} 335}$ and Malme $3 \mathrm{M}^{\mathrm{R}-}$ miR-335 cells showed lower invasion potential than SNU387 ${ }^{R}$ and

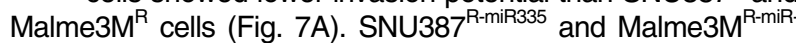
${ }_{335}$ cells showed lower expression of SNAIL than SNU387 ${ }^{\mathrm{R}}$ and Malme3M ${ }^{R}$ cells (Fig. 7A). SNU387 $7^{R-m i R-335}$ and Malme3M ${ }^{R-m i R-}$ ${ }^{335}$ cells also showed lower migration potential than SNU387 ${ }^{\mathrm{R}}$ and Malme3M ${ }^{R}$ cells (Fig. 7B). Taken together, these results suggest that miR-335 regulates the response to anti-cancer drugs by affecting the invasion and migration potential of cancer cells.

miR-335 regulates the tumorigenic potential and growth potential of cancer cells

We next examined whether miR-335 affects the tumorigenic potential of cancer cells. It is well known that anti-cancer drugresistance is correlated with higher tumorigenic potential (Kim et al., 2014). The xenograft of Malme $3 \mathrm{M}^{R}$ cells showed a higher tumorigenic potential than the xenograft of Malme3M $\mathrm{M}^{\mathrm{R}-\mathrm{miR}-335}$ cells (Fig. 8A). The xenograft of Malme $3 M^{R}$ cells showed resistance to celastrol and taxol while the xenograft of Malme $3 \mathrm{M}^{\mathrm{B}-\mathrm{miR}-335}$ cells showed sensitivity to celastrol and taxol (Fig. 8A). Malme3M ${ }^{\text {R-miR-335 }}$ cells showed lower growth than Malme $3 \mathrm{M}^{\mathrm{R}}$ cells (Fig. 8B). Western blot of tumor tissue lysates showed that the lower tumorigenic potential of Malme $3 \mathrm{M}^{\mathrm{R}-\mathrm{miR}-335}$ cells was associated with the lower expression levels of SIAH2, MDR1, and SNAIL in comparison to Malme3M ${ }^{R}$ cells (Fig. 8C). Malme $3 \mathrm{M}^{\mathrm{R}-\mathrm{miR}-335}$ cells showed lower anchorage-independent gowth potential than Malme $3 \mathrm{M}^{\mathrm{R}}$ cells (Fig. 8D). Taken together, these results suggested that the effect of miR-335 on the response to anti-cancer drugs is associated with its effect on the tumorigenic potential and growth potential of cancer cells.

\section{DISCUSSION}

The SIAH family of proteins interacts with $\mathrm{N}-\mathrm{CoR}$, an HDAC3interacting protein. Silencing $\mathrm{SIAH} 2$ leads to increased caspase activity and apoptosis in response to both TRAIL and Fas ligand (Christian et al., 2011). Our results show that SIAH2 regulates expression of HDAC3 and induces the ubiquitination of HDAC3 (Fig. 2B). TBL1 and TBLR1 function as ubiquitin ligases and are involved in HDAC3 degradation (Zhao et al., 2010; Dimitrova et al., 2010). It would be interesting to examine the effects of these ubiqutin ligases on the expression of HDAC3.

Acetylation is an important post-translational modification that regulates various cellular processes (Shan et al., 2014). The acetylation of HDAC3 is increased in SNU387 ${ }^{R}$ and Malme $3 M^{R}$ cell lines (data not shown). In this study, we found that Tip60, a histone acetyl transferase, was necessary for acetylation of HDAC3 (data not shown). It will be necessary to examine the 
effect of Tip60 on the expression of HDAC3 and the response to anti-cancer drugs. Knockdown of HDAC3 in cells increases TIP60 acetylation levels after DNA damage (Yi et al., 2014). HDAC3 and Tip60 may thus form a negative feedback loop.

In this study, we found that taxol decreased HDAC3 expressionwhile increasing the level of active rac1 in anticancer cancer cell lines (data not shown). This suggested that rac1 might regulate the expression of HDAC3. In addition, we found tyrosine nitration of HDAC3 in anti-cancer drug-resistant cancer cell lines such as Malme $3 \mathrm{M}^{\mathrm{R}}$ and $\mathrm{SNU} 387^{\mathrm{R}}$ cells (data not shown). The activated Rac1/Cdc42 enhances p53 protein ubiquitination and weakens p53 protein stability to increase VEGF expression (Ma et al., 2013). ubiquitination of HDAC3 by rac1 requires further study.

miR-335 acts as a metastasis suppressor in gastric cancer by targeting Bcl-w and specificity protein 1 (Xu et al., 2012). miR-335 inhibits tumor re-initiation and is epigenetically silenced in breast cancers (Png et al., 2011). miR-335 suppresses neuroblastoma cell invasiveness by down regulating multiple genes from TGF- $\beta$ signaling pathways (Lynch et al., 2012). miR-335 down-regulates ROCK and MAPK1, resulting in reduced phosphorylation of downstream signaling molecules (Lynch et al., 2012). It will be interesting to examine the roles of ROCK1 and MAPK1 in resistance to anti-cancer drugs. The miR-335/SIAH2/HDAC3 axis possibly regulates MAPK.

Target Scan analysis revealed the binding of miR-326 to the $3^{\prime}$ UTR of HDAC3. miR-326 is involved in chemo-resistance in breast cancer cell by modulating expression of multi drug resistance-associated protein 1 (Liang et al., 2010). miR-326 regulates the response to anti-cancer drugs by forming a negative feedback loop with HDAC3 (Kim et al., 2014). It will be interesting to examine whether miR-326 induces the expression of SIAH2 and the ubiquitination of HDAC3. It is probable that miR-326 may negatively regulate the expression of miR335 to decrease the expression of HDAC3.

miRNA array analysis showed that miR-138 is decreased in Malme3M $\mathrm{M}^{\mathrm{R}}$ cells (Fig. 3A). miR-138 increases radio-sensitivity in lung cancer cells by up-regulating the expression of $\gamma-\mathrm{H} 2 \mathrm{AX}$ (Yang et al., 2014). The down-regulation of miR-138-5p contributes to gefitinib resistance in non- small cell lung cancer (Gao et al., 2014). It will be necessary to examine whether anticancer drugs, such as taxol, affects the expression of miR-138. miRNA array analysis also showed that the expression of miR211 is lower in Malme3M ${ }^{R}$ cells than in Malme3M cells (Fig. 3A). miR-211, a melanocyte lineage-specific small non-coding miRNA, acts as a tumor suppressor by regulating the activity of oncogenes such as PRAME and KCNMA1 (Mazar et al., 2010; Sakurai et al., 2011). miR-211 suppresses the invasion potential of melanoma cells (Levy et al., 2010; Mazar et al., 2010). The induction of the miR-211 expression in the cells increases the sensitivity to gemcitabine and reduced the expression of its target ribonucleotide reductase subunit 2 (RRM2) (Maftouh et al., 2014). miR-211 overexpression leads to the activation of the intrinsic mitochondrial/Caspase-9/3-mediated apoptotic pathway in glioma and cancer stem cells (CSC) (Asuthkar et al., 2012). miR-211 targets MMP-9 and forms a negative feedback loop with MMP-9 (Asuthkar et al., 2012). qRT-PCR analysis showed that the expression of miR-138 and miR-211 is lower in various anti-cancer drug-resistant cancer cell lines than in anticancer drug-sensitive cancer cell lines (data not shown). It will be necessary to further identify targets of miR-138 and/or miR211 for better understanding of the mechanism of anti-cancer drug-resistance.

miR-146 targets SIAH2 (Liao et al., 2013). miR-146a/b-
TRAF6/IRAK1-NF-KB axis regulates dendritic cell apoptosis (Park et al., 2015). The down-regulation of miR-146a and miR$146 \mathrm{~b}$ increases the expression of anti-apoptotic protein Bcl-2 (Park et al., 2015). It will be necessary to examine whether miR146a/-146b regulate the expression of HDAC3.

HDAC3, along with c-Myc, represses the expression of miR15a/miR-16-1 (Zhang et al., 2012). It will be interesting to furthet identify miRNAs that are regulated by HDAC3. So far, there are few known HDAC3-regulated miRNAs. miRNAs that are increased in anti-cancer drug-resistant cancer cells may form a negative feedback loop with HDAC3. In conclusion, the miR-335-SAIH2-HDAC3 axis offers a valuable target for the development of anti-cancer drugs.

\section{ACKNOWLEDGMENTS}

This work was supported by National Research Foundation Grants (2014R1A2A2A01002448,2015R1A1A3A04001339), a grant from the BK21 Plus Program, and by National R\&D Program for Cancer Control, Ministry for Health and Welfare, Republic of Korea Grant 1320160. This work was also supported by a grant from Kangwon National University.

\section{REFERENCES}

Asuthkar, S., Velpula, K.K., Chetty, C., Gorantla, B., and Rao, JS (2012). Epigenetic regulation of miRNA-211 by MMP-9 governs glioma cell apoptosis, chemosensitivity and radiosensitivity. Oncotarget 3, 1439-1454

Bardai, F.H., and D'Mello, S.R. (2011). Selective toxicity by HDAC3 in neurons: regulation by Akt and GSK3beta. J. Neurosci. 31, 1746-1751.

Calin, G. A., and Croce, C. M. (2006). MicroRNA signatures in human cancers. Nat. Rev. Cancer 6, 857-866.

Cao, J., Cai, J., Huang, D., Han, Q., Yang, Q., Li, T., Ding, H., and Wang, Z. (2013). miR-335 represents an invasion suppressor gene in ovarian cancer by targeting Bcl-w. Oncol Rep. 30, 701706.

Chan, P., Möller, A., Liu, M.C., Sceneay, J.E., Wong, C.S., Waddell, N., Huang, K.T., Dobrovic, A., Millar, E.K., O'Toole, S.A., et al. (2011). The expression of the ubiquitin ligase SIAH2 (seven in absentia homolog 2) is mediated through gene copy number in breast cancer and is associated with a basal-like phenotype and p53 expression. Breast Cancer Res. 13, R19.

Chen, L.F., Fischle, W., Verdin, E., and Greene, W.C. (2001). Duration of nuclear NF-kappaB action regulated by reversible acetylation. Science 293, 653-1657.

Chen, Z., Ma, T., Huang, C., Zhang, L., Lv, X., Xu, T., Hu, T., and Li, J. (2013). miR-27a modulates the MDR1/P-glycoprotein expression by inhibiting FZD7/ $\beta$-catenin pathway in hepatocellular carcinoma cells. Cell. Signal. 25, 2693-2701.

Cheng, W. Liu, T., Wan, X., Gao, Y., and Wang, H. (2012). MicroRNA- 199a targets CD44 to suppress the tumorigenicity and multidrug resistance of ovarian cancer-initiating cells. FEBS J. 279, 2047-2059.

Christian, P.A., Fiandalo, M.V., and Schwarze, S.R. (2011). Possible role of death receptor-mediated apoptosis by the E3 ubiquitin ligases Siah2 and POSH. Mol. Cancer 10, 57.

Dimitrova, Y.N., Li, J., Lee, Y.T., Rios-Esteves, J., Friedman, D.B., Choi, H.J., Weis, W.I., Wang, C.Y., and Chazin, W.J. (2010). Direct ubiquitination of beta-catenin by Siah-1 and regulation by the exchange factor TBL1. J. Biol. Chem. 285, 13507-13516.

Dohi, O., Yasui, K., Gen, Y., Takada, H., Endo, M., Tsuji, K., Konishi, C., Yamada, N., Mitsuyoshi, H., Yagi, N., et al. (2013). Epigenetic silencing of miR-335 and its host gene MEST in hepatocellular carcinoma. Int. J. Oncol. 42, 411-418.

Gao, Y., Fan, X., Li, W., Ping, W., Deng, Y., and Fu, X. (2014). miR$138-5 p$ reverses gefitinib resistance in non-small cell lung cancer cells via negatively regulating $G$ protein-coupled receptor 124. Biochem. Biophys. Res. Commun. 446, 179-186.

Grishina, I., Debus, K., García-Limones, C., Schneider, C., Shresta, A., García, C., Calzado, M.A., and Schmitz, M.L. (2012). SIAH- 
mediated ubiquitination and degradation of acetyl-transferases regulate the p53 response and protein acetylation. Biochim. Biophys. Acta 1823, 2287-2296.

Hsieh, S.C., Kuo, S.N., Zheng, Y.H., Tsai, M.H., Lin, Y.S., and Lin, J.H. (2013). The E3 ubiquitin ligase SIAH2 is a prosurvival factor overexpressed in oral cancer. Anticancer Res. 33, 4965-4973.

Katakowski, M., Zheng, X., Jiang, F., Rogers, T., Szalad, A., and Chopp, M. (2010). MiR-146b-5p suppresses EGFR expression and reduces in vitro migration and invasion of glioma. Cancer Invest. 28, 1024-1030.

Kim, H.C., Choi, C., Choi, H.K., Kang, H.B., Kim, M.J., Lee, Y.H., Lee, O.H., Lee, J., Kim, Y.J., Jun, W., et al. (2010). HDAC3 selectively represses CREB3-mediated transcription and migration of metastatic breast cancer cells. Cell. Mol. Life. Sci. 67, 3499-3510.

Kim, Y., Park, D., Kim, H., Choi, M., Lee, H., Lee, Y.S., Choe, J., Kim, Y.M., and Jeoung D. (2013). miR-200b and cancer/testis antigen CAGE form a feedback loop to regulate the invasion and tumorigenic and angiogenic responses of a cancer cell line to microtubule-targeting drugs. J. Biol. Chem. 288, 36502-36518.

Kim, Y., Kim, H., Park, H., Park, D., Lee, H., Lee, Y.S., Choe, J., Kim, Y.M., and Jeoung, D. (2014). miR-326-histone deacetylase-3 feedback loop regulates the invasion and tumorigenic and angiogenic response to anti-cancer drugs. J. Biol. Chem. 289, 28019-28039.

Levy, C., Khaled, M., lliopoulos, D., Janas, M.M., Schubert, S., Pinner, S., Chen, P.H., Li, S., Fletcher, A.L., Yokoyama, S., et al. (2010). Intronic miR-211 assumes the tumor suppressive function of its host gene in melanoma. Mol. Cell 40, 841-849.

Li, J., Wang, J., Wang, J., Nawaz, Z., Liu, J.M., Qin, J., and Wong, J. (2000). Both corepressor proteins SMRT and N-CoR exist in large protein complexes containing HDAC3. EMBO J. 19, 43424350.

Liang, Z., Wu, H., Xia, J., Li, Y., Zhang, Y., Huang, K., Wagar, N., Yoon, Y., Cho, H.T., Scala, S., et al. (2010). Involvement of miR326 in chemotherapy resistance of breast cancer through modulating expression of multidrug resistance-associated protein 1. Biochem. Pharmacol. 79, 817-824.

Liao, Y., Zhang, M., and Lönnerdal, B. (2013). Growth factor TGF- $\beta$ induces intestinal epithelial cell (IEC-6) differentiation: miR-146b as a regulatory component in the negative feedback loop. Genes Nutr. 8, 69-78.

Longworth, M.S., and Laimins, L.A. (2006). Histone deacetylase 3 localizes to the plasma membrane and is a substrate of Src. Oncogene 25, 4495-4500.

Lynch, J., Fay, J., Meehan, M., Bryan, K., Watters, K.M., Murphy, D.M., Stallings, R.L. (2012). MiRNA-335 suppresses neuroblastoma cell invasiveness by direct targeting of multiple genes from the non-canonical TGF- $\beta$ signalling pathway. Carcinogenesis 33, 976-985

Ma, J., Xue, Y., Liu, W., Yue, C., Bi, F., Xu, J., Zhang, J., Li, Y., Zhong, C., and Chen, Y. (2013). Role of activated Rac1/Cdc42 in mediating endothelial cell proliferation and tumor angiogenesis in breast cancer. PLoS One 8, e66275.

Ma, B., Chen, Y., Chen, L., Cheng, H., Mu, C., Li, J., Gao, R., Zhou, C., Cao, L., Liu, J., et al. (2015). Hypoxia regulates Hippo signalling through the SIAH2 ubiquitin E3 ligase. Nat. Cell Biol. 17, 95103.

Maftouh, M., Avan, A., Funel, N., Frampton, A.E., Fiuji, H., Pelliccioni, S. Castellano, L. Galla, V., Peters, G.J., and Giovannetti, E. (2014). miR-211 modulates gemcitabine activity through downregulation of ribonucleotide reductase and inhibits the invasive behavior of pancreatic cancer cells. Nucleosides Nucleotides Nucleic Acids 33, 384-393.

Mahlknecht, U., Emiliani, S., Najfeld, V., Young, S., and Verdin, E. (1999). Genomic organization and chromosomal localization of the human histone deacetylase 3 gene. Genomics 56, 197-202.

Mahlknecht, U., Will, J., Varin, A., Hoelzer, D., and Herbein, G. (2004). Histone deacetylase 3 , a class I histone deacetylase, suppresses MAPK11-mediated activating transcription factor-2 activation and represses TNF gene expression. J. Immunol. 173, 3979-3990.

Martin, N.T., Nakamura, K., Davies, R., Nahas, S.A., Brown, C., Tunuguntla, R., Gatti, R.A., and Hu, H. (2013). ATM-dependent MiR-335 targets CtIP and modulates the DNA damage response. PLoS Genet. 9, e1003505.

Mazar, J., DeYoung, K., Khaitan, D., Meister, E., Almodovar, A.,
Goydos, J., Ray, A., and Perera, R.J. (2010). The regulation of miRNA-211 expression and its role in melanoma cell invasiveness. PLoS One 5, e13779.

Mosquera, J., Armisen, R., Zhao, H., Rojas, D.A., Maldonado, E., Tapia, J.C., Colombo, A., Hayman, M.J., and Marcelain, K. (2011). Identification of Ski as a target for Aurora A kinase. Biochem. Biophys. Res. Commun. 409, 539-543.

Nakayama, K., Frew, I.J., Hagensen, M., Skals, M., Habelhah, H., Bhoumik, A., Kadoya, T., Erdjument-Bromage, H., Tempst, P., Frappell, P.B., et al. (2014). Siah2 regulates stability of prolylhydroxylases, controls HIF1alpha abundance, and modulates physiological responses to hypoxia. Cell 117, 941-952.

Park, D., Park, H., Kim, Y., Kim, H., and Jeoung D. (2014a). HDAC3 acts as a negative regulator of angiogenesis. BMB Rep. 47, 227232.

Park, H., Kim, Y., Park, D., and Jeoung, D. (2014b). Nuclear localization signal domain of HDAC3 is necessary and sufficient for the expression regulation of MDR1. BMB Rep. 47, 342-347.

Park, H., Huang, X., Lu, C., Cairo, M.S., and Zhou, X. (2015). MicroRNA-146a and MicroRNA-146b Regulate Human Dendritic Cell Apoptosis and Cytokine Production by Targeting TRAF6 and IRAK1 Proteins. J. Biol. Chem. 290, 2831-2841.

Pietschmann, K, Buchwald, M., Müller, S., Knauer, S.K., Kögl, M., Heinzel, T., and Krämer, O.H. (2012). Differential regulation of PML-RAR $\alpha$ stability by the ubiquitin ligases SIAH1/SIAH2 and TRIAD1. Int. J. Biochem. Cell. Biol. 44, 132-138.

Png, K.J., Yoshida, M., Zhang, X.H., Shu, W., Lee, H., Rimner, A Chan, T.A., Comen, E., Andrade, V.P., Kim, S.W., et al. (2011) MicroRNA-335 inhibits tumor reinitiation and is silenced through genetic and epigenetic mechanisms in human breast cancer. Genes Dev. 25, 226-231.

Qi, J., Nakayama, K. Gaitonde, S., Goydos, J.S., Krajewski, S. Eroshkin, A., Bar-Sagi, D., Bowtell, D., and Ronai, Z. (2008). The ubiquitin ligase Siah2 regulates tumorigenesis and metastasis by HIF-dependent and -independent pathways. Proc. Natl. Acad. Sci. USA 105, 16713-16718.

Sakurai, E., Maesawa, C., Shibazaki, M., Yasuhira, S., Oikawa, H Sato, M., Tsunoda, K., Ishikawa, Y., Watanabe, A., Takahashi, K., et al. (2011). Downregulation of microRNA-211 is involved in expression of preferentially expressed antigen of melanoma in melanoma cells. Int. J. Oncol. 39, 665-672.

Sarkar, T.R., Sharan, S., Wang, J., Pawar, S.A., Cantwell, C.A., Johnson, P.F., Morrison, D.K., Wang, J.M., and Sterneck, E. (2012). Identification of a Src tyrosine kinase/SIAH2 E3 ubiquitin ligase pathway that regulates $\mathrm{C} / \mathrm{EBP} \delta$ expression and contributes to transformation of breast tumor cells. Mol. Cell. Biol. 32, 320-332.

Scarola, M., Schoeftner, S., Schneider, C., and Benetti, R. (2010). miR-335 directly targets Rb1 (pRb/p105) in a proximal connection to p53-dependent stress response. Cancer Res. 70, 69256933.

Shah, M., Stebbins, J.L., Dewing, A., Qi, J., Pellecchia, M., and Ronai, Z.A. (2009). Inhibition of Siah2 ubiquitin ligase by vitamin K3 (menadione) attenuates hypoxia and MAPK signaling and blocks melanoma tumorigenesis. Pigment Cell Melanoma Res. 22, 799-808

Shan, X., Fu, Y.S., Aziz, F., Wang, X.Q., Yan, Q., and Liu, J.W. (2014). Ginsenoside Rg3 Inhibits Melanoma Cell Proliferation through Down-Regulation of Histone Deacetylase 3 (HDAC3) and Increase of p53 Acetylation. PLoS One 9, e115-401.

Sorrentino, A., Liu, C.G., Addario, A., Peschle, C., Scambia, G., and Ferlini, C. (2008). Role of microRNAs in drug-resistant ovarian cancer cells. Gynecol. Oncol. 111, 478-486.

Tomé, M., López-Romero, P., Albo, C., Sepúlveda, J.C., Fernández-Gutiérrez, B., Dopazo, A., Bernad, A., and González, M.A. (2011). miR-335 orchestrates cell proliferation, migration and differentiation in human mesenchymal stem cells. Cell Death Differ. 18, 985-995.

Uo, T., Veenstra, T.D., and Morrison, R.S. (2009). Histone deacetylase inhibitors prevent p53-dependent and p53independent Bax-mediated neuronal apoptosis through two distinct mechanisms. J. Neurosci. 29, 2824-2832.

Wang, H., Li, M., Zhang, R., Wang, Y., Zang, W., Ma, Y., Zhao, G., and Zhang, G. (2013). Effect of miR-335 upregulation on the apoptosis and invasion of lung cancer cell A549 and H1299. Tumour Biol. 34, 3101-3109. 
Wong, C.S., Sceneay, J., House, C.M., Halse, H.M., Liu, M.C., George, J., Hunnam, T.C., Parker, B.S., Haviv, I., Ronai, Z., et al. (2012). Vascular normalization by loss of Siah2 results in increased chemotherapeutic efficacy. Cancer Res. 72, 1694-1704.

Xiong, S.W., Lin, T.X., Xu, K.W., Dong, W., Ling, X.H., Jiang, F.N. Chen, G., Zhong, W.D., and Huang, J. (2013). MicroRNA-335 acts as a candidate tumor suppressor in prostate cancer. Pathol. Oncol. Res. 19, 529-537.

Xu, Y., Zhao, F., Wang, Z., Song, Y., Luo, Y., Zhang, X., Jiang, L. Sun, Z., Miao, Z., and Xu, H. (2012). MicroRNA-335 acts as a metastasis suppressor in gastric cancer by targeting Bcl-w and specificity protein 1 . Oncogene $31,1398-1407$.

Xu, X., Chen, H., Lin, Y., Hu, Z., Mao, Y., Wu, J., Xu, X., Zhu, Y., Li, S., Zheng, X., and Xie, L. (2013). MicroRNA-409-3p inhibits migration and invasion of bladder cancer cells via targeting c-Met Mol. Cells 36, 62-68.

Yan, Z., Xiong, Y., Xu, W., Gao, J., Cheng, Y., Wang, Z., Chen, F., and Zheng, G. (2012). Identification of hsa-miR-335 as a prognostic signature in gastric cancer. PLoS One 7, e40037.
Yang, H., Tang, Y., Guo, W., Du, Y., Wang, Y., Li, P., Zang, W., Yin, X., Wang, H., Chu, H., et al. (2014). Up-regulation of microRNA138 induce radiosensitization in lung cancer cells. Tumour Biol. 35, 6557-6565.

Yi, J., Huang, X., Yang, Y., Zhu, W.G., Gu, W., and Luo, J. (2014). Regulation of histone acetyltransferase TIP60 function by histone deacetylase 3. J. Biol. Chem. 289, 33878-33886.

Zhang, J., Kalkum, M., Chait, B.T., and Roeder, R.G. (2002). The $\mathrm{N}$-CoR-HDAC3 nuclear receptor corepressor complex inhibits the JNK pathway through the integral subunit GPS2. Mol. Cell 9 , 611-623.

Zhang, X., Chen, X., Lin, J., Lwin, T., Wright, G., Moscinski, L.C., Dalton, W.S., Seto, E., Wright, K., Sotomayor, E., et al. (2012). Myc represses miR-15a/miR-16-1 expression through recruitment of HDAC3 in mantle cell and other non-Hodgkin B-cell lymphomas. Oncogene 31, 3002-3008.

Zhao, H.L., Ueki, N., and Hayman, M.J. (2010). The Ski protein negatively regulates SIAH2-mediated HDAC3 degradation. Biochem. Biophys. Res. Commun. 399, 623-628. 